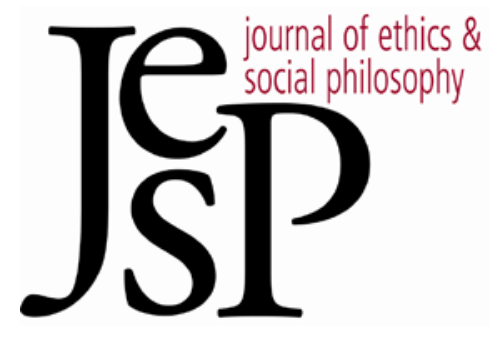

\title{
Reducing Reasons
}

\author{
by MattheW Silverstein
}

JOURNAL OF ETHICS \&SOCIAL PHILOSOPHY

Vol. 10, NO. 1 | FEBRUARY 2016 URL: WWW.JESP.ORG COPYRIGHT (C MATTHEW SILVERSTEIN 2016 


\title{
Reducing Reasons
}

\author{
Matthew Silverstein
}

$\mathrm{R}$ EASONS ARE CONSIDERATIONS THAT FIGURE in reasoning. When I believe or act for a reason, my reason plays a role in the reaall of the reasons for which I believe or act are good reasons; not all explanatory reasons are normative or justifying reasons. ${ }^{1}$ If reasons in general are considerations that figure in reasoning, normative reasons are considerations that figure in sound reasoning.

This broad view about the connection between normative reasons and sound reasoning is widely held.2 Those who hold it often regard it as obvious - boring, even. As Kieran Setiya puts it:

It is a harmlessly illuminating principle that connects two things which surely must be connected: facts being reasons ..., on one side, and the process of ... thinking, inference, deliberation, on the other. ${ }^{3}$

Jonathan Way describes the link between reasons and reasoning as "near platitudinous":

Reasons are meant to guide us to act, believe, desire, or otherwise respond. But to be guided by reasons just is to engage in reasoning, broadly construed. So it is hard to see how reasons could fail to be appropriate premises for reasoning towards $\varphi$ ing. ${ }^{4}$

The idea of a connection between normative reasons and sound reasoning does seem platitudinous. However, I think it actually has surprising and farreaching metanormative implications. The view that reasons are linked to sound reasoning may strike us as "harmlessly illuminating," but only because

\footnotetext{
1 Many philosophers use the term "motivating reason" to refer to the reasons for which we act or believe. I prefer the term "explanatory reason" for the reasons outlined by J. D. Velleman (2004) "Replies to Discussion on The Possibility of Practical Reason," Philosophical Studies 121(3): 279. In adopting this terminology, I do not mean to deny that there are various considerations that figure in explanations but that are not reasons for which anything is done or believed.

2 See for instance J. Raz (1975) Practical Reason and Norms, London: Hutchinson \& Co., p. 28; B. Williams (1981) "Internal and External Reasons," in Moral Luck, Cambridge: Cambridge University Press, pp. 103-4; J. D. Velleman (1989) Practical Reflection, Princeton: Princeton University Press, ch. 7; R. Audi (2004) "Reasons, Practical Reason, and Practical Reasoning," Ratio 17(2): 119-45; P. Hieronymi (2005) “The Wrong Kind of Reason," Journal of Philosophy 102(9): 437-57; K. Setiya (2007) Reasons without Rationalism, Princeton: Princeton University, p. 12, and (2014) "What Is a Reason to Act?" Philosophical Studies 167(2): 221-35; and J. Way (forthcoming) "Reasons as Premises of Good Reasoning," Pacific Philosophical Quarterly.

3 Setiya (2014: 223).

4 Way (forthcoming: 1).
} 
we tend to assume that soundness is a normative property, in which case the view merely relates one normative phenomenon (reasons) to another (soundness). I shall argue, though, that soundness is also a descriptive phenomenon, one we can pick out with purely descriptive terms, and that the connection between normative reasons and sound reasoning therefore provides the basis for a reductive account of reasons. Like all proposed reductions, this one must confront some version of G. E. Moore's open question argument. I shall argue that a reductive view rooted in the idea that reasons figure in sound reasoning is well equipped to meet the open question challenge head on.

1.

Following both Setiya and Way, I shall take as my starting point the idea that normative reasons are premises in sound reasoning. More specifically, I shall follow Way in supposing that a consideration $R$ is a reason for some response $\varphi$ just in case $R$ is a premise in sound reasoning that concludes in $\varphi$-ing. ${ }^{5}$

As Way has pointed out, the hypothesis that reasons are premises of sound reasoning sheds light on a number of puzzles about reasons. It explains what the various kinds of reasons - reasons for action, reasons for belief, reasons for desire, and so forth - have in common, why we can have normative reasons only for attitudes we can reach through reasoning, and why some of the considerations that count in favor of a response are the wrong kind of reason for that response. ${ }^{6}$ The hypothesis also raises a number of questions, the most pressing of which concerns the nature of soundness. Just what is sound reasoning? The short answer is that sound reasoning is good or correct reasoning: to reason soundly is to reason well - to reason as one should. If that is all we can say about soundness, then the hypothesis that normative reasons figure in sound reasoning really will be harmless. I believe we can say more, though. I accept the short answer: sound reasoning is good or correct reasoning, and so soundness is indeed a normative property. However, I think it is also a descriptive property - a property that can be grasped or picked out in purely descriptive terms. To argue for this surprising conclusion, I shall begin with the case of doxastic reasoning, or reasoning about what to believe. I shall then argue that we can understand the soundness of

5 Compare Way (forthcoming: 6). Of course, a consideration can be a normative reason without anyone acting for that reason. So, the reasoning in which a normative reason figures as a premise need not be a train of thought undertaken or followed by any actual agent. Put another way, that some consideration figures as a premise in sound reasoning is not a psychological claim about how anyone has actually reasoned. Rather, it is a claim about how one might reason, and do so soundly. A consideration counts as a reason, then, just in case there is some possible course of sound reasoning in which it figures as a premise. Note that I use the general term "response" to refer to the category of things (including, presumably, various attitudes as well as actions) we can have or do for a reason.

${ }^{6}$ For the details of these explanations, see Way (forthcoming: 7-10). 
any form of reasoning along the same lines we understand the soundness of doxastic reasoning.

2.

As we teach students in introductory logic courses, deductively sound doxastic reasoning is just deductively valid doxastic reasoning from true premises. Truth is not a normative concept. Nor, plausibly, is validity. An argument or a bit of reasoning is valid just in case there are no possible worlds in which all of the premises are true and the conclusion false. Validity therefore looks more like a modal concept than a normative one. And in that case soundness does as well: we can identify an instance of deductive doxastic reasoning as sound without deploying any normative concepts. ${ }^{7}$

This appearance could be misleading, of course. After all, sound reasoning is supposed to be good or correct reasoning, and there are all sorts of unsettled questions about the relation between valid reasoning and good or correct reasoning. It is widely accepted, for instance, that not all valid inferences are good inferences. Suppose that I believe that $p$ and that I come to believe that if $p$, then $q$. If I then infer that $q$, my inference is clearly valid. Yet it may not be the correct inference: if I have strong independent reasons to think that $q$ is false and relatively weak reasons to believe that $p$, then surely I ought to give up my belief that $p$. Surely, in other words, I should reason in accordance with modus tollens here rather than modus ponens. Either inference would be val$\mathrm{id}$, but only one of them is correct. Likewise, if I reason from contradictory premises to the conclusion that all unicorns are white, then - on at least some accounts of deductive validity - my reasoning is valid. But it is also clearly problematic. We must therefore be careful before concluding that we can understand sound deductive reasoning in purely logical terms.

Yet in the cases where deductively valid reasoning falls short of good or correct reasoning, adding that the premises are true takes us the rest of the way. Given any conditional, for instance, we can reason soundly in only one direction. Suppose that I correctly believe that if $p$, then $q$. If $p$ is true, then modus ponens is the sound inference. If $p$ is false, then modus tollens is the sound inference. Similarly, we need not worry about inferences from contradictory premises, since no such inference can be sound. This suggests that we do not need to settle questions about the relation between valid reasoning and correct reasoning in order to capture the soundness of deductive doxastic reasoning in purely descriptive terms. There are no instances of deductively sound reasoning that fail to be instances of good or correct reasoning, even though there are instances of bad or incorrect deductively valid reasoning.

7 Here I am appealing to an account of logic like the one defended by G. Harman (1986) Change in View: Principles of Reasoning, Cambridge, MA: MIT Press, ch. 2. For an argument to the effect that logic is essentially normative, see H. Field (2009) "What Is the Normative Role of Logic?" Proceedings of the Aristotelian Society, Supplementary Volumes 81(1): 251-68. 
There is more to doxastic reasoning than deductive syllogisms, however. Most doxastic deliberation consists of inductive or abductive reasoning. Yet it is quite plausible that we can also make sense of the soundness of these other forms of reasoning in purely descriptive terms. As in the deductive case, sound inductive reasoning proceeds from true premises. The connection between the truth of the premises and the truth of the conclusion is much looser when it comes to inductive reasoning, though. In a sound inductive inference, although the truth of the premises does not necessitate the truth of the conclusion, it does probabilize the conclusion or render it more likely. As formal epistemologists are fond of saying, it confirms the conclusion. Of course, it also justifies or counts in favor of our believing the conclusion, and thus it is tempting to conclude that the relation between the premises of a sound inductive inference and the conclusion is a normative one. We need not resist that temptation: it is indeed a normative relation. But it is also a descriptive one - one we can grasp in purely descriptive terms. Although sound inductive reasoning is just correct inductive reasoning, it is also just reasoning in which true premises probabilize or confirm the conclusion. If this is correct, then the soundness of doxastic reasoning is a descriptive property as well as a normative one.

We might want to reserve the honorific "sound" for instances of doxastic reasoning in which one takes into account all of the available considerations that bear on the truth of the proposition about which one is deliberating. Suppose I notice that there is water falling outside my window and then conclude on the basis of that observation that it is raining. Is my reasoning sound? It may depend on what else I know. For instance, if I know that it almost never rains here, that there is not a cloud in the sky, and that the windows above mine are currently being washed, then presumably I would not be reasoning soundly were I to conclude that it is raining. My reasoning would be sound only if I accorded due weight to these other relevant considerations, and were I to do so I would quickly conclude that the water falling outside my window has nothing to do with rain. There appears, then, to be more to sound doxastic reasoning than realizing that some consideration confirms or otherwise supports the truth of some conclusion and then accepting that conclusion on the basis of that realization.

We can still grasp the differences between sound and unsound doxastic reasoning in purely descriptive terms, however. We can capture the full scope of this stronger conception of sound reasoning by taking our original account and adding that the premises of sound reasoning must include all of one's true beliefs that bear one way or the other on the truth of the conclusion. This ideal of soundness is probably never realized, of course. But the various ways in which our doxastic reasoning falls short can be articulated descriptively. Sometimes we draw conclusions that are not confirmed or otherwise supported by our premises. Other times we fail to incorporate relevant considerations in our deliberations. And other times we reason from false premises. So even though soundness with respect to doxastic reasoning 
comes in degrees, the differences among those degrees all appear to be descriptive matters.

This account of sound doxastic reasoning is likely to be controversial. Some will object to my suggestion that the logical relations that hold between the premises of a sound deductive inference and its conclusion can be grasped in purely descriptive terms. Others will complain that the notion of confirmation that figures in my account of sound inductive reasoning is irreducibly normative. These are reasonable worries, but I shall not discuss them further here. In the sections that follow, I shall instead outline a general theory of sound reasoning that takes this account of sound doxastic reasoning as its model. I shall argue that if we can understand the soundness of doxastic reasoning in purely descriptive terms, then we can understanding the soundness of any kind of reasoning in purely descriptive terms.

3.

Reasoning always has an aim. For every kind of reasoning, there must be something that counts as success. Take as an example practical reasoning the kind of reasoning that usually concludes in an intention or action. One account of the aim of practical reasoning is uncontroversial: practical reasoning aims at figuring out what to do. This characterization, though accurate, is incomplete. It specifies only the formal object of practical reasoning, and as J. David Velleman has argued - "any enterprise that has a formal object must have a substantive object as well - that is, a goal that is not stated solely in terms that depend on the concept of being the object of that enterprise"::

In the case of a competitive game, there must be a substantive object of the game, something that constitutes winning but cannot simply consist in winning, so described. A game whose object was specifiable only as "winning" wouldn't have an object - that is, wouldn't have any object in particular. And if a game had no particular object, then there would be no such thing as winning it, and so it wouldn't be a fully constituted competitive game. Similarly, a hunt whose object was specifiable only as "the quarry" wouldn't be a fully constituted search, and the question "What is the answer?" isn't by itself a fully constituted question. 9

Practical reasoning as well, then, must have a substantive object or aim: there must be something at which practical reasoning aims in virtue of which it aims at figuring out what to do. "A mode of reasoning whose goal was specified solely as 'figuring out what to do' would be like a search whose object was specified solely as 'figuring out where to look,' or a question whose object was specified solely as "figuring out how to reply."' 10

8 J. D. Velleman (1996) “The Possibility of Practical Reason,” Ethics 106(1): 700-1.

9 Ibid.: 701

10 Ibid.: 701-2. This means that Allan Gibbard's account of the nature of practical reasoning in (2003) Thinking How to Live, Cambridge, MA: Harvard University Press, pp. 3-8, is radically incomplete. There must be more to practical reasoning than the search for "the thing to do" 
The same goes for other kinds of reasoning. Return for a moment to the case of doxastic reasoning. Formally characterized, the aim of doxastic reasoning is figuring out what to believe. There must be more to the aim than this, though. Doxastic reasoning must also have a substantive object or aim. As it happens, most philosophers accept a familiar account of this object namely, the view that doxastic reasoning aims at the truth. Although there is less agreement about the respective aims of other forms of reasoning (and especially about the aim of practical reasoning), it remains clear that for each of them there must be some substantive object at which it aims.

Less clear is what is involved in reasoning having an aim. With respect to doxastic reasoning, the metaphor of aiming is cashed out by different philosophers in different ways. Some take the fact that doxastic reasoning aims at the truth to be a descriptive fact about the mechanisms causally regulating deliberation about what to believe. Others also take it to be conceptual truth about correctness conditions for belief. For our purposes here, the weaker, teleological claim will suffice. It will be enough for doxastic reasoning to have the aim of truth if it is regulated by mechanisms geared to produce true beliefs. The same goes for other forms of reasoning. For any distinctive kind of reasoning, there will be something substantive we are attempting to settle in engaging in that reasoning, and this aim will be operative in whatever mechanisms causally regulate our deliberations. Moreover, if - as most philosophers believe - reasoning is an essentially rule-governed activity, then the aim of a particular form of reasoning will at least be implicit in the rules of inference that govern that reasoning.

How can we come to know the aim of a particular form of reasoning? In some cases we may observe it directly - perhaps in the phenomenology of the relevant sort of deliberation. Nishi Shah has argued, for instance, that the aim of belief is revealed in the phenomenology of doxastic deliberation: "[W]ithin the perspective of first-person doxastic deliberation ... one cannot settle on an answer to the question whether to believe that $p$ without taking oneself to have answered the question whether $p$ is true." 11 In other cases, our evidence may be more indirect. Velleman contends that hypotheses about the aim of practical reasoning earn credibility "by explaining various otherwise

(7). Of course, "the thing to do" is indeed what we are looking for when we are deliberating about what to do, but we cannot look for it solely under that description, just as we cannot conduct a search for something that is described solely as "the thing we are looking for." There must be a mark in virtue of which something counts as the thing for which we are searching if our activity is to constitute a genuine search. Similarly, there must be some mark in virtue of which a course of action counts as the thing to do, and practical reasoning must involve the search for that mark.

Setiya (2007) acknowledges that practical reasoning has a substantive aim but argues that this aim cannot provide a standard of success or correctness for practical reasoning because it is too easy for agents to achieve (107-15). I address Setiya's argument in (2010) "The Standards of Practical Reasoning," Philosophical Quarterly 60(20): 671-78.

11 N. Shah (2003) "How Truth Governs Belief," Philosophical Review 112(4): 447. 
inexplicable aspects of agency." 12 He defends his own startling hypothesis that practical reasoning aims at intelligibility along precisely such lines. According to Velleman, this hypothesis can explain, among other things, how actions can be attributed to agents rather than to other events, how - from the deliberative point of view, at least - we have an open future, how we often know what we are doing without observation, how our intentions guide and constrain our future actions and deliberations, and how we sometimes act contrary to our better judgment. The evidence available may be different from one kind of reasoning to the next - and it may frequently go unnoticed - but we should nevertheless expect that each distinctive form of reasoning will display marks of its respective aim somewhere.

4.

What does all of this have to do with sound reasoning? I believe that the fact that every form of reasoning must have a substantive aim entails that we can understand the soundness of every form of reasoning much as we understand the soundness of doxastic reasoning.

Consider practical reasoning again. As we have already seen, the fact that practical reasoning must have a substantive aim means that there must be some mark we are trying to identify whenever we are attempting to figure out what to do. When we engage in practical reasoning, the action we are trying to identify is the action that most completely displays that mark, whatever it is. We can therefore measure the soundness of practical reasoning against that mark, just as we measure the soundness of doxastic reasoning against the aim of truth.

It may be helpful here, following Pamela Hieronymi, to think of reasoning in terms of questions. According to Hieronymi, reasoning is the attempt to answer or settle a question. Certain attitudes and actions - those formed on the basis of reasoning - embody one's answers to the relevant questions. ${ }^{13}$ Practical reasoning is the attempt to answer the question what to do, doxastic reasoning is the attempt to answer the question what to believe, and so forth. But these are merely formal characterizations of the questions that drive practical and doxastic reasoning. They correspond to the formal aims of reasoning discussed by Velleman. There must be more to practical reasoning than the question what to do. That is, there must be some other, more substantive question we are attempting to settle when we attempt to settle the question what to do, and the intention or action with which our reasoning concludes will therefore embody our answer to this more substantive question.

Suppose, then - just for the purposes of illustration - that Jeremy Bentham's psychological hedonism is true. According to Bentham, "nature has placed mankind under the governance of two sovereign masters, pain and

12 Velleman (2004: 288).

13 Hieronymi (2005: 443-44). 
pleasure. It is for them alone ... to determine what we shall do." ${ }_{14}$ One way to interpret Bentham here is as making a claim about practical reasoning: practical reasoning aims at identifying the most pleasurable course of action. If Bentham is correct, then - as Hieronymi would put it - when we engage in deliberation about what to do, we are attempting to settle a substantive question about pleasure: What is the most pleasurable course of action? And once we have identified this question, we can understand the soundness of practical reasoning in terms borrowed from our discussion of the soundness of doxastic reasoning. Our attempt to answer the question that drives practical reasoning - and thus our reasoning itself - will be sound if and only if the premises upon which we rely in arriving at our answer are true and confirm or otherwise support that answer.

We must tread carefully, though, for Hieronymi's talk of questions and answers may make this move appear simpler than it really is. My application of the model of soundness drawn from doxastic reasoning to the practical case may seem straightforward only because it can be difficult to see how the answer to a question one asks oneself could be anything other than a judgment or belief. Returning to the Bentham example, it is difficult to see how the answer to the question "What is the most pleasurable course of action?" could be anything other than a judgment or belief to the effect that this (where "this" denotes some act) is the most pleasurable course of action. Now, it is certainly easy to see how the truth of the premises of practical reasoning could confirm or otherwise support the truth of a conclusion that looks like that. But this is just because practical reasoning now looks an awful lot like a kind of doxastic reasoning - namely, doxastic reasoning on the subject of pleasure. The same will hold for any form of reasoning so long as we think about the conclusion of that form of reasoning as the answer to a substantive question. ${ }^{15}$

${ }^{14} \mathrm{~J}$. Bentham (1996/1789) An Introduction to the Principles of Morals and Legislation, J. H. Burns and H. L. A. Hart, eds., Oxford: Clarendon Press, p. 11. According to Montaigne, this view was once universally accepted: "All the opinions in the world agree on this - that pleasure is our goal" ((1958) “That to Philosophize Is to Learn to Die," in D. M. Frame, trans., The Complete Essays of Montaigne, Stanford: Stanford University Press, p. 56).

${ }^{15}$ Hieronymi urges us not to take her metaphorical talk of questions and answers too literally. She maintains that all sorts of attitudes can "embody their subject's answer to some question" ((2009) "Two Kinds of Agency," in L. O’Brien and M. Soteriou, eds., Mental Actions, Oxford: Oxford University Press, p. 138). For example, "having settled for oneself (positively) the question of whether to $\varphi$..., one therein intends to $\varphi$ " (138). That may seem reasonable, and it may not seem to entail that practical reasoning is just a species of doxastic reasoning. Yet we cannot understand practical reasoning merely as the attempt to settle the question of whether to $\varphi$. That is at most a formal description of the aim of practical reasoning, and as Velleman argues, there must also be a substantive description of that aim. Once we frame the question that drives practical reasoning in the terms of that substantive description, it will be much harder to resist the conclusion that the outcome of practical reasoning is a judgment. How could anything other than a judgment constitute an answer to a substantive question? Of course, we can always simply stipulate that attitudes like resentment and intention can "embody" one's answers to questions, but once we do that the metaphor of 
Of course, plenty of philosophers - cognitivists about practical reasoning - maintain that the conclusion of practical reasoning really is a belief about some substantive matter, and thus that practical reasoning just is a species of doxastic reasoning. ${ }^{16}$ Were we to accept cognitivism, then any application of my descriptive account of the soundness of doxastic reasoning to the case of practical reasoning would be unnecessary, for we would already have an account of the latter simply in virtue of having one of the former. Yet cognitivism about practical reasoning is controversial, to say the least: most philosophers of action believe that practical reasoning concludes either in a distinctively practical attitude or in an action. ${ }^{17}$ Fortunately, the success of my reductive proposal does not hinge on the truth of cognitivism. We need not assume that the conclusion of practical reasoning is a belief in order to tell a descriptive story about sound practical reasoning that parallels the familiar descriptive story about sound doxastic reasoning. Cognitivism would make that story especially tidy, but it is not essential.

Suppose, then - pace cognitivism - that practical reasoning normally concludes in an action. Such reasoning must still be governed by a substantive aim, and the rules of inference in practical reasoning must still be conducive to achieving that aim. But this means that the premises of a practical inference will support the concluding action just in case those same premises would confirm or support the belief that that action achieves the relevant aim better than any available alternative. Put more schematically, if the distinctive aim of practical reasoning is $A$, then practical reasoning that concludes in $\varphi$-ing will be sound just in case doxastic reasoning that proceeded from the same premises and concluded in the belief that $\varphi$-ing best achieves $A$ would be sound. This follows merely from the idea that practical reasoning is governed by a substantive aim.

To see how, return once again to Bentham's hedonism. If practical reasoning aims at pleasure, then the rules of inference in practical reasoning must be pleasure-conducive - that is, they must be designed to point us in the direction of the most pleasurable actions. We reason in accordance with the rules of practical reasoning, then, only to the extent that the premises of

questions and answers starts to seem pointless, for we start to lose our grip on what it means to say that reasoning is the attempt to answer a question. I am indebted to Nishi Shah for helpful discussion of Hieronymi's view.

16 Cognitivism about practical reasoning has a distinguished pedigree. Its proponents over the past 50 years include R. Audi (1973) "Intending," Journal of Philosopby 70(13): 387-403; G. Harman (1976) "Practical Reasoning," Review of Metaphysics 29(3): 431-63; W. A. Davis (1984) "A Causal Theory of Intending," American Philosophical Quarterly 21(1): 43-54; Velleman (1989, chs. 3-4); and Setiya (2007: 21-56).

${ }_{17}$ For the former view, see M. Bratman (1987) Intention, Plans, and Practical Reason, Cambridge, MA: Harvard University Press. For the latter view, often associated with Aristotle, see S. Tenenbaum (2007) "The Conclusion of Practical Reason," in Moral Psychology, Amsterdam: Rodopi; and J. Dancy (2009) "Action, Content and Inference," in J. Hyman and H. Glock, eds., Wittgenstein and Analytic Philosophy: Essays for P. M. S. Hacker, Oxford: Oxford University Press, pp. 278-98. 
our reasoning support the conclusion that the action we ultimately perform is the most pleasurable one available to us. Consider a specific instance of practical reasoning. If I were to choose one book over another because it was recommended by Oprah Winfrey, my practical reasoning would be sound only if the rule of following Oprah's book recommendations were pleasureconducive. But this rule would be pleasure-conducive only if the fact that Oprah recommended a book confirmed or otherwise supported the conclusion that the book would provide pleasure. And so my practical reasoning in this case - that is, my reasoning from Oprah's recommendation to my choice of the recommended book - would be sound only if the corresponding doxastic reasoning were sound. The soundness of the former is nothing more than a reflection of the soundness of the latter.

Crucially, none of this depends on the details of Bentham's view. We could construct a structurally identical argument given any account of practical reasoning's substantive aim. Moreover, none of this depends on the reasoning under consideration being practical reasoning. Take any form of reasoning you like: reasoning about what to desire, resent, admire, or respect. It must be regulated by a substantive aim. And thus the soundness of that form of reasoning will mirror the soundness of doxastic reasoning about the relevant aim.

I think we should actually accept a stronger conclusion here, for I believe that this is just what the soundness of reasoning consists in. In other words, I think there is more than a merely biconditional relation here. If practical reasoning aims at pleasure, then my choosing a book on the basis of Oprah's recommendation is sound reasoning because that recommendation constitutes evidence that the book will provide more pleasure than the alternatives. Put another way, the fact that Oprah recommended this book figures in sound practical reasoning in virtue of the fact that it is evidence for the conclusion that the book is the most pleasurable one available. This suggests that - if Bentham is right about the aim of practical reasoning - sound practical reasoning just is reasoning in which true premises confirm or otherwise support the conclusion that the chosen action is the most pleasurable of those available. And if the difference between sound and unsound practical reasoning can be articulated in purely descriptive terms, then the property of soundness turns out to be both normative and descriptive. The same goes for the property of being a reason for action, at least if reasons are just considerations that figure in sound reasoning. The normative property of being a reason for action turns out to be identical to the descriptive property of being evidence that some course of action will maximize $A$, where $A$ is the aim of practical reasoning.

Of course, when we are dealing with apparently normative properties like soundness, we cannot simply assume that necessary co-extension entails identity. Philosophers opposed to reductionism in metaethics will maintain that even if it is necessarily true that reasoning is sound just in case it has some descriptive property - and, for that matter, even if it is necessarily true 
that reasoning is sound because (or in virtue of the fact that) it has that descriptive property - the soundness of reasoning cannot be identical to (and thus reduced to) that descriptive property. This opposition to reduction is rooted in the intuition that drives G. E. Moore's open question argument - namely, the thought that the normative is "just too different" from the descriptive for the former to be reducible to the latter. ${ }^{18}$ Below I shall argue that however appropriate this reaction may be when we are confronted with other reductive proposals, it arises with nowhere near the same force here. First, though, I shall pause to situate my view vis-à-vis some related accounts of reasons.

\section{5.}

One challenge facing the view that normative reasons are premises of sound reasoning is to account for the different "weights" of reasons. Most reasons are pro tanto: they count in favor of some response but can be outweighed or overridden by other reasons. The fact that some consideration is a good reason for me to $\varphi$ is perfectly consistent with there being other, better reasons for me not to $\varphi$. So, while there may be something to be said for my $\varphi$-ing, there may be much more to be said for my $\psi$-ing.

This seems like a problem for the view that reasons are premises of sound reasoning. After all, if a reason is outweighed by countervailing considerations, then surely reasoning from that consideration to the conclusion it supports would be unsound. For example, the fact that I promised to meet you at the airport is a reason for me to do so. But if I can save lives by breaking my promise (and leaving you to take a taxi), then surely reasoning from the fact that I promised to the intention to pick you up would be unsound. We seem to have a reason - the fact that I promised - that does not figure as a premise in sound reasoning that concludes with the action favored by that reason.

Setiya attempts to solve this problem by casting his version of the view that reasons are premises of sound reasoning in terms of motivation. According to Setiya, a reason to $\varphi$ "is a premise for sound reasoning to a desire or motivation to $\varphi . "{ }_{19}$ This looks like a solution because sound reasoning can move me to $\varphi$ while also and to a much greater extent moving me to $\psi$. When it does, my reason to $\varphi$ will figure in sound reasoning that concludes in my being moved to $\varphi$ without figuring in sound reasoning that concludes in my $\varphi$-ing. So, although I would be reasoning unsoundly were I to deliberate from the fact that I promised to pick you up at the airport to my intending to do so (at least given the countervailing considerations), my reasoning would be perfectly sound were I to deliberate from the fact that I promised to pick you up to my merely being moved to do so, so long as I was more strongly

18 D. Enoch (2011) Taking Morality Seriously: A Defense of Robust Realism, Oxford: Oxford University Press, p. 100.

${ }^{19}$ Setiya (2014: 221, emphasis added). 
moved to break my promise and save lives instead. Setiya's appeal to motivation as the conclusion of sound reasoning also provides him with a straightforward account of the weight of reasons: "[W]e can measure the relative weight of reasons by the relative strength of motivation." 20

Way complains that although Setiya's approach works well when applied to reasons for action, it makes less sense when applied to reasoning that concludes in an attitude like belief or admiration, for it is not at all clear how we should understand the idea of being motivated to believe or to admire. I worry there is a more basic problem here, though. Once I realize I can save lives by breaking my promise and leaving you to find your own way home from the airport, I am not moved or motivated to pick you up at all. I recognize that my promise counts in favor of picking you up, but this just does not motivate me in the face of the countervailing considerations. Of course, I may regret that I will not be there to meet you, but I need not feel any motivational tug (or nudge) in the direction of the airport. If that is correct, then it is a mistake to identify the normative force of a reason with the motivation produced by sound deliberation from that reason.

My preferred solution to the problem of pro tanto reasons more closely resembles Way's. Way observes that "we can distinguish between the claim that it is [sound] reasoning to move from the belief that $p$ to $\varphi$-ing and the claim that it is [sound] reasoning to move from the belief that $p$ to $\varphi$-ing given further attitudes you might have." ${ }_{21}$ So, although I would be reasoning soundly were I to deliberate from the fact that I promised to pick you up to the intention to do so, I would not be reasoning soundly were I to arrive at this conclusion if my premises included the further thought that I could save lives by breaking my promise. Reasoning from my promise to the intention to pick you up is sound but defeasible: it is defeated by reasoning that incorporates the additional premise about saving lives and that concludes with the corresponding intention. The weights of reasons, then, are a function of the defeasibility of the sound reasoning in which they figure. More specifically, where $p$ is a reason to $\varphi$ and $q$ is a reason to $\psi, p$ outweighs $q$ if the sound reasoning in which $p$ figures defeats the sound reasoning in which $q$ figures.

My suggestion above that there are degrees of soundness mirrors Way's claim that sound reasoning can be defeated. Way never explains what soundness involves, though, and so we are left wondering precisely how reasons count in favor of the responses for which they are reasons. My view provides illumination here. Reasons count in favor of the responses for which they are reasons by being evidence that those responses will achieve the aim of the relevant sort of reasoning. Sound reasoning that concludes in $\varphi$-ing defeats sound reasoning that concludes in $\psi$-ing just in the case the evidence that $\varphi$-ing will achieve the relevant aim is stronger than the evidence that $\psi$-ing will achieve that aim.

20 Setiya (2014: 229).

21 Way (forthcoming: 20, emphasis added). 
A reason, then, is evidence; and the stronger the evidence, the weightier the reason.

Now, however, my account of reasons is starting to look like a version of the account proposed by Stephen Kearns and Daniel Star. According to Kearns and Star, "a reason to $\varphi$ is simply evidence that one ought to $\varphi$. ." 22 If we assume that the aim of reasoning is always to arrive at an all-thingsconsidered "ought"-judgment, then these two views are essentially indistinguishable. If, for instance, the aim of practical reasoning is to do what one ought to do, then the view that a reason to $\varphi$ is a premise in sound reasoning that concludes in $\varphi$-ing just amounts to the view that a reason to $\varphi$ is evidence that one ought to $\varphi .23$

The reductionist agenda motivating my view sets it apart from Kearns and Star's, though. Like Way's, my account purports to be a constitutive account of reasons: it is supposed to shed light on what it is to be a reason. ${ }^{24}$ It will also be a reductive account only if it identifies what it is to be a reason in purely descriptive terms. And this means that, unlike Kearns and Star, I must reject the idea that practical reasoning - or any other sort of reasoning, for that matter - is necessarily carried out under the guise of the normative. ${ }^{25}$ If practical reasoning aims at doing what we ought to do under that description, then the view that reasons are premises in sound reasoning, together with my account of soundness, will not yield a reductive account of reasons for action. Reasons for action will be considerations that figure in reasoning that is explicitly about what one ought to do, and we will therefore need some independent grip on facts about what we ought to do before we can better understand what reasons are. It is a presupposition of my account, then, that practical reasoning need not be carried out under the guise of the normative.26 Without this presupposition, we cannot understand what it is to be a

22 S. Kearns and D. Star (2009) "Reasons as Evidence," Oxford Studies in Metaethics 4: 216.

23 All of these views - Setiya's, Way's, Kearns and Star's, and mine - must address Jonathan Dancy's claim that some of the considerations that figure as premises in reasoning (and that are evidence for the relevant conclusion) are enabling (or disabling) conditions or intensifiers (or attenuators), rather than reasons. I do not have the space to address Dancy's arguments here. The line of response I favor is broadly in keeping with replies Kearns and Star offer in "Weighing Reasons" (2003) Journal of Moral Philosophy 10: 84-86, as well as with some (but not all) of Setiya's replies in (2014: 226-28).

24 Compare Way (forthcoming: 6).

25 Although they never take up the question explicitly, Kearns and Star do suggest at various points that practical reasoning is explicitly about what one ought to do. In the course of defending their view, for instance, they note that "by 'reliable practical reasoning' we mean practical reasoning that is generally successful in terms of issuing in correct judgments concerning what it is one ought to do" (2009: 224).

26 I defend this presupposition elsewhere; see "Ethics and Practical Reasoning" (unpublished manuscript). In denying that practical reasoning is carried out under the guise of the normative, I follow a long line of distinguished philosophers of action, including H. Frankfurt (2004) "Disengaging Reason," in R. J. Wallace, P. Pettit, S. Scheffler and M. Smith, eds., Reason and Value: Themes from the Philosophy of Joseph Raz, Oxford: Oxford University Press, pp. 
reason for action in purely descriptive terms, in which case a unifying and reductive account of reasons is off the table.

6.

The most familiar objection to reductive accounts of reasons is that they fail to capture what is distinctive about reasons - namely, their normativity. Our insight into the nature of reasons extends beyond the specific reasons we grasp. We also understand, at least to some extent, what it is to be a reason. This generally implicit understanding is reflected in various platitudes about reasons, such as: reasons count in favor of the actions or attitudes for which they are reasons; reasons have a special kind of authority over our responses and our deliberations; reasons guide our behavior and attitudes; judgments about reasons have a motivational or practical upshot; and so forth. The standard objection to reductive accounts of reasons is rooted in the conviction that any such account will fail to do justice to at least some of these platitudes. According to this objection, no descriptive property can play all of the roles the property of being a reason is supposed to play, and a theory that cannot capture all of these roles cannot be correct. Whatever descriptive property that theories identifies, then, it must be something other than the property of being a reason.

Versions of this worry figure prominently in discussions of metanormative reductionism. In their survey of fin de siècle ethics, Stephen Darwall, Allan Gibbard, and Peter Railton suggest that resistance to reductionism on these grounds is one of the lasting legacies of Moore's open question argument. For although Moore's argument is not "a proof of a fallacy," it nevertheless "brings to the fore certain characteristic features of ... normative [properties] ... that seem to stand in the way of our accepting" a reductive account of those properties. ${ }^{27}$ With respect to any reductionist proposal that explicates the property of being a normative reason in terms of some descriptive property $P$, it seems perfectly coherent to acknowledge that $x$ is $P$

122-27; J. D. Velleman (1992) "The Guise of the Good," Nô̂s 26(1): 3-26; M. Bratman (2003) “A Desire of One's Own," Journal of Philosophy 100(5): 221-42; and Setiya (2007).

Interestingly, even if practical reasoning is carried out under the guise of something other than the normative, there remains a sense in which my view is a version of Kearns and Star's view that reasons to $\varphi$ are evidence that one ought to $\varphi$, at least if we accept that one ought to $\varphi$ just in case one has most reason to $\varphi$. On my view, a reason to $\varphi$ is evidence that $\varphi$-ing would achieve the aim of the relevant sort of reasoning. It is also, therefore, evidence that $\varphi$-ing is what one has most reason to do. If one ought to $\varphi$ just in case one has most reason to $\varphi$, then a reason will also be evidence that one ought to $\varphi$. Crucially, though, it will be evidence that one ought to $\varphi$ in virtue of being evidence that $\varphi$-ing would best achieve the aim of the relevant sort of reason. It is this final thought that distinguishes my account from Kearns and Star's. On my view, practical reasoning does aim at doing what one ought to do, but not under that description.

27 S. Darwall, A. Gibbard and P. Railton (1992) "Toward Fin de Siècle Ethics: Some Trends," Philosophical Review 101(1): 116. 
while also wondering whether $x$ is genuinely a reason. According to Darwall, Gibbard, and Railton, this question's intelligibility at least "appears to call for some [account of reasons] other than the reductionist proposal." ${ }_{28}$ David Enoch expresses similar concerns when he claims that normative facts and properties are "just too different from [descriptive] ones to be a subset of them." ${ }_{29}$ The distinctiveness of normative properties leads Thomas Nagel to conclude that "if values are objective, they must be so in their own right, and not through reducibility to some other kind of objective fact. They have to be objective values, not objective anything else." ${ }_{30}$

I take these sorts of worries to be the most significant challenge confronting reductive accounts of reasons. ${ }^{31}$ I believe that the view I outlined above is uniquely well-equipped to meet this challenge, however.

One feature often associated with the normativity of reasons involves guidance: reasons for action are considerations for which we can act, reasons for belief are considerations for which we can believe; and so forth. The view that reasons are considerations that figure in sound reasoning clearly captures this aspect of their normativity. Consider reasons for action. If practical reasoning is reasoning that issues in an intention or action, I act for some reason by arriving at an intention or performing an action on the basis of reasoning in which that reason figures as a premise. A reason guides my behavior by figuring in an actual instance of my practical reasoning and thereby playing a role

28 Darwall, et. al. (1992: 177). For similar takes on the antireductionist significance of the open question argument, see P. Railton (1989) "Naturalism and Prescriptivity," Social Philosophy and Policy 7(1): 158; D. Wiggins (1993) "A Neglected Position?" in J. Haldane and C. Wright, eds., Reality, Representation, and Projection, New York: Oxford University Press, pp. 33034; C. Rosati (1995) "Naturalism, Normativity, and the Open Question Argument," Noûs 29(1): 46-70, and (2003) "Agency and the Open Question Argument," Ethics 113(3): 490-527;

T. M. Scanlon (1998) What We Owe to Each Other, Cambridge, MA: Harvard University Press, pp. 57-60; R. Shafer-Landau (2003) Moral Realism: A Defence, Oxford: Clarendon Press, p. 95; and C. R. Pigden (2012) "Identifying Goodness," Australasian Journal of Philosophy 90(1): 93109.

${ }^{29}$ Enoch (2011: 100). Compare Derek Parfit's "normativity objection" in (2011) On What Matters, Vol. 2, Oxford: Oxford University Press, pp. 324-27.

${ }^{30}$ T. Nagel (1986) The View from Nowhere, Oxford: Oxford University Press, p. 138.

31 This is not the only challenge, of course. Reductive accounts also face questions of extensional adequacy - worries that they are inconsistent with our judgments or intuitions about the reasons we have. I do not dwell on such worries here. For one thing, in the absence of an account of the aim or object of a particular kind of reasoning, my reductive proposal does not tell us much about which considerations are reasons and which are not. It merely tells us that our reasons, whatever they are, will be a function of the point or aim of the relevant sort of reasoning. Since I am not offering an account of the point or aim of any kind of reasoning, we are not yet in any position to evaluate the overall extensional adequacy of the view I have proposed. What is more, at least some degree of extensional revision should be expected on any reductive view. The whole point of reduction is to shed light on something we do not yet fully understand. And as Darwall, Gibbard, and Railton have urged, once we acknowledge that our intuitive notions of soundness and of a reason are plagued by at least some degree of confusion or ambiguity, we can "hardly expect ... any philosophical account of them that is not itself confused and ambiguous [to] have just the right intuitive "fit"' (1992: 178). 
in the production of my intention or action. An analogous story can be told for various other kinds of normative reasons.

There is more to the normativity of reasons than guidance, though. Reasons do not merely guide; they do so with authority. It is with respect to this distinctive sort of authority that so many reductive accounts of the normative fall short. Does the view articulated here fare any better? Notice first that according to this view, normative force is more than the merely motivational or guiding force exerted by considerations that figure in reasoning. Considerations can figure in reasoning without doing so soundly: they can be false or irrelevant (and thereby fail to support or confirm the truth of the relevant conclusion). A normative reason must be more than a guide; it must be a sound guide. A reason for action, for instance, must be more than merely practical or motivational; it must be soundly practical. A consideration exhibits normative force or authority, then, by playing a role in sound reasoning - reasoning in which true premises provide genuine support for a conclusion. The normative force of reasons therefore involves more than guidance. It is also a kind of logical force.32 On my view it is soundness - or the logical force of truth and evidence - that plays the role of normative authority.

I believe that it plays this role quite convincingly. Considerations of soundness have undeniable authority over our reasoning. One cannot engage in reasoning without attempting to do so soundly, for the whole point of reasoning is to arrive at a conclusion that is supported by true premises. To return once again to Bentham's psychological hedonism, if practical reasoning aims at pleasure, then the whole point of practical reasoning is to arrive at the most pleasurable course of action. And in that case it seems undeniable that evidence about which course of action would be the most pleasurable has authority over my deliberations. This is why I think the reductionist approach I am proposing can meet the open question challenge head on. The connection between reasons and sound reasoning seems no less platitudinous than it did before. There just does not seem to be any room to question whether a consideration that bears on sound reasoning is a reason. With respect to any consideration that figures in sound deliberation concluding with your $\varphi$-ing, it does not seem to be an open question whether that consideration is a reason for you to $\varphi$ (or whether it counts in favor of your $\varphi$-ing). Put more schematically, if $A$ is the distinctive aim of reasoning about whether to $\varphi$, then it does not seem to be an open question whether evidence that $\varphi$-ing would best achieve $A$ is a reason to $\varphi$. It makes no sense to wonder

32 This is why I do not characterize my view as a form of reductive naturalism. I am not at all confident that the logical notion of validity - and its probabilistic or confirmational counterparts in the inductive and abductive realm - can be understood in naturalistic terms. Does this lessen the interest in my reductive proposal? It might, if the only motivation for reduction is a prior commitment to metaphysical naturalism. If, on the other hand, the motivation for reduction is the opacity or "queerness" of normativity - and if, for whatever reason, logic, modality and probability seem less queer or problematic - then the reduction will provide an illuminating explanation of something that would otherwise remain opaque. 
whether you have reason to act or to believe in accordance with the conclusion of sound reasoning, even once we understand soundness in terms of the relevant aim or object. Moreover, it is difficult to see how any other kind of consideration could authoritatively govern our deliberations and close the relevant question in this way. Only considerations of evidence or soundness seem to have the kind of authority over our reasoning that reasons are supposed to have.

One might worry that my view does not close the open question so much as relocate it. Even if there is no room to question whether a consideration that bears on sound reasoning really is a reason, it may seem that there is room to question whether reasoning that satisfies my descriptive account of soundness really is sound. ${ }^{33}$ Suppose that $A$ is the distinctive aim of some form of reasoning, and suppose that the bulk of the evidence supports the conclusion that $\varphi$-ing would best achieve $A$. Is it an open question whether reasoning that concludes in $\varphi$-ing and that does so on the basis of that evidence is sound? It certainly does not seem to be an open question in the doxastic case. And, as I argued above, if it does not look like an open question with respect to doxastic reasoning, then it should not look like an open question with respect to any other sort of reasoning, at least once we take seriously the idea that reasoning is always driven by a substantive object or aim. Were we genuinely to accept Bentham's suggestion that practical reasoning aims at pleasure, I think it would not appear to be an open question whether reasoning that concluded in the most pleasurable action (and that did so on the basis of the relevant evidence) is sound.

I suspect that questions of this sort seem open to many philosophers at least when they are questions about sound practical reasoning - only because these philosophers cannot envision a plausible account of the substantive aim of practical reasoning that is supported by nonnormative considerations. If you are not convinced that practical reasoning aims at pleasure - and I have nowhere suggested that you should be - then of course the question of whether sound practical reasoning involves only considerations of pleasurability will seem wide open. Actually, given that Bentham's view is wildly implausible, the question probably seems closed but in the opposite direction. Yet my proposed reduction does not rest on any particular account of the aim of practical reasoning. It rests merely on the idea that some substantive aim drives practical reasoning. We may never discover this aim; the evidence may be too diffuse and thin. But I maintain that if we were to discover it, we would thereby close the question of what sound practical reasoning involves.

33 I am grateful to Nishi Shah, Kevin Coffey, and an anonymous referee for pressing me on this point. 
7.

To see just how well my view captures the normative authority of reasons and closes the open question, it may be helpful to compare it with two prominent, competing reductive accounts of reasons: Mark Schroeder's hypotheticalism and Sharon Street's constructivism.

Consider first Schroeder's view, presented most completely in his book, Slaves of the Passions. According to Schroeder, what makes something a reason for me to act is that it is appropriately related to the object of one of my desires. More specifically:

For all propositions $r$, agents $x$, and actions $a$, if $r$ is a reason for $x$ to do $a$, that is because there is some $p$ such that $x$ has a desire whose object is $p$, and the truth of $r$ is part of what explains why $x$ 's doing $a$ promotes $p .34$

Schroeder presents this thesis as a reductive account of the property of being a reason for action, and he acknowledges that it must therefore confront some version of the open question argument. In particular, it must confront Enoch's charge that the property of being a reason is "just too different" to be reducible to any descriptive property, and thus that any purportedly reductive account of the former will accomplish nothing more than a change of subject. Schroeder's task, in short, is to demonstrate that his account of reasons for action captures rather than eliminates their normativity.

Schroeder contends that the best way to meet this challenge is to show that his account of reasons is not wildly out of sync with our considered intuitions about what we do and do not have reason to do. And so he devotes the central chapters of his book to arguing for this conclusion. But even if these kinds of extensional concerns can be alleviated, open question worries remain. Even if the property of being a reason is largely (or entirely) coextensive with the property of being related in the appropriate way to the object of one of my desires, we may still have good reason to deny that the former can be reduced to the latter. 35 In particular, we may have good reason to conclude that the latter property lacks some of the features in virtue of which the former is normative. It may share some of those features, of course. For example, it is easy enough to see how I might be guided by a consideration in virtue of that consideration's being appropriately related to the object of one of my desires. It is less easy to see, however, how such a consideration has any kind of authority over me or my deliberations. Schroeder's view entails that my wanting something endows the object of my want with a special kind of authority over my practical deliberations. Actually, it entails

${ }^{34}$ M. Schroeder (2007) Slaves of the Passions, Oxford: Oxford University Press, p. 30. Schroeder is concerned only with reasons for action here, and so the comparison will be limited but still, hopefully, illustrative.

35 Schroeder himself rejects the view that necessary co-extensiveness is sufficient for property identity. See ibid.: 67-72. 
something more - namely, that this is just what that special kind of authority consists in. But the mere fact that I desire something does not seem to involve or give rise to any sort of authority. If I ask you what it is for something to be a reason for me to act, and you reply by describing the relevant relation to the things I desire, I may reasonably complain that you have changed the subject. There is more to the authority of reasons for action than the fact that they reveal the ways in which I might satisfy my desires or achieve my ends, whatever they happen to be. ${ }^{36}$

The problem here is that the thing Schroeder has tasked with playing the role of normative authority is not doing so convincingly. This is what casts doubt on his proposed reduction. Notice that similar doubts cannot be cast on the view I have proposed. If I ask you what it is for something to be a reason for me to act, and you reply by describing the role considerations can play in sound practical reasoning, then I cannot reasonably accuse you of having changed the subject. Soundness is plausibly cast as the source of the authority of reasons for action, whereas desire is only implausibly so cast. That is why we should prefer my proposed reduction to Schroeder's.

What about Street's constructivism? According to Street, normative questions are "questions about what is entailed from within the standpoint of a creature who values things" or judges things to be valuable. ${ }^{37}$ We answer such questions simply by determining what follows from a creature's evaluative standpoint. Translated into an account of reasons, this becomes:

The fact that $X$ is a reason to $Y$ for agent $A$ is constituted by the fact that the judgment that $X$ is a reason to $Y$ (for $A$ ) withstands scrutiny from the standpoint of $A$ 's other judgments about reasons. ${ }^{38}$

Street does not take the notion of what is entailed by one's other normative judgments - or of what withstands scrutiny from the standpoint of one's other normative judgments - to be normative. Rather, it is something like a logical notion, which is what lends her constructivism its reductive air. ${ }^{39}$ On the re-

${ }^{36}$ Compare Warren Quinn: "How can a ... state whose central significance in this context is to help explain our tendency to act toward a certain end, or in accordance with a certain principle, rationalize our pursuit of the end or our deference to the principle? How can the fact that we are set up to go in a certain direction make it (even prima facie) rational to decide to go in that direction? How can it even contribute to its rationality?" ((1993) "Putting Rationality in Its Place," in Morality and Action, Cambridge: Cambridge University Press, p. 236). See also T. M. Scanlon (2014) Being Realistic about Reasons, Oxford: Oxford University Press, pp. 6-7.

37 S. Street (2010) "What Is Constructivism in Ethics and Metaethics?" Philosophy Compass 5(5): 374 .

38 S. Street (2008) "Constructivism about Reasons," Oxford Studies in Metaethics 3: 223.

39 Actually, it is more than a logical notion. It is also a constitutive notion, insofar as what withstands scrutiny from the standpoint of your normative judgments is partly a function of what is constitutive of holding such judgments. See Street (2008: 227-31). It is ultimately unclear in what sense Street's constructivism is reductive. For her discussion of this issue, see Street (2008: 239-42). For doubts about whether this sort of constructivism constitutes a 
sulting view, facts about reasons consist in nothing more than facts about what follows from within the point of view of one's other normative judgments. We therefore come to understand what it is for something to be a reason by first understanding the attitude of taking or judging something to be a reason, where that attitude is supposed to be one on which we have some sort of prior and independent purchase.

Once again, though, open question worries remain, for it is not at all clear whether Street's constructivism captures the normativity of reasons. Of course, as was the case with Schroeder's hypotheticalism, it is easy to see how reasons function as guides on Street's view. It is less easy to see how they do so with any authority, however. To be sure, if we presuppose that our starting set of normative judgments is authoritative, then it certainly makes sense to treat the judgments that genuinely withstand scrutiny from the standpoint of that starting set as similarly authoritative. But why should we ascribe any authority to those initial judgments? Just as there is nothing terribly authoritative about my desiring something, so is there nothing terribly authoritative about my judging that I have a reason to do or to believe something. I may just be wrong. According to Street, this judgment acquires authority by withstanding scrutiny from the standpoint of my other normative judgments, but that only pushes the question back: Whence comes the authority of those judgments?

The worry here is not that Street has no answer to this question. After all, her answer will be the same as before: the authority of these judgments stems from the fact that they withstand scrutiny from the standpoint of my other normative judgments (and, presumably, from the standpoint of one another). Rather, the worry is that it is not clear why their withstanding such scrutiny would endow them with any authority over my deliberations. That is, it is not clear why my coherently judging these considerations to be reasons would make it the case that they really are reasons.

Street's constructivism is rooted in the idea that there is something authoritative about verdicts delivered from the normative point of view, and thus something authoritative about the normative point of view itself. But the normative point of view is just the point of view of one's judgments about reasons. So, the capacity to withstand scrutiny from the standpoint of those judgments is what plays the role of normative authority on Street's view. Lingering suspicions of open questions suggest that it plays this role unconvincingly. If I ask you what it is for $p$ to be a reason for me to $\varphi$, and you reply by describing the way in which the judgment that $p$ is a reason for me to $\varphi$ follows from within my normative point of view, I may again reasonably complain that you have changed the subject. There must be more to the authority of normative reasons than the fact that my judging them to be

determinate account of reasons for action, see N. Shah (2010) "The Limits of Normative Detachment," Proceedings of the Aristotelian Society 110(3): 357-59. 
reasons would withstand scrutiny from the standpoint of my other judgments about reasons, whatever they happen to be. ${ }^{40}$

Street might argue that the authority of our other normative judgments resides in the fact that the process of teasing out the logical and constitutive implications of our normative judgments (together with the nonnormative facts) just is the process of reasoning. ${ }^{41}$ In other words, she might argue that the standpoint of our other normative judgments is authoritative in virtue of the fact that it is the standpoint we adopt when we engage in reasoning. That certainly seems like a step in the right direction, at least with respect to the kind of open question worries we are currently considering. But notice that it is also a step in the direction of my proposed view. On this alternative understanding of Street's constructivism, reasons are considerations that figure in sound reasoning, where reasoning is just reasoning from one's normative judgments (together with the nonnormative facts) to further normative judgments. Yet now it is the account of the nature of sound reasoning - or of the aim of reasoning - that is pulling all of the normative weight. Once Street's view has been formulated as a version of my view, it can meet the open question challenge with ease..$^{42}$

What makes the reduction I have proposed more plausible than these alternatives is the intrinsic authority that considerations of soundness (or evidence) have over one's reasoning. Neither one's desires (as on Schroeder's view) nor one's normative judgments (as on Street's view) are similarly authoritative.

40 Street's most powerful response to this worry is to point out that the open question argument is only one source of pressure on our understanding of reasons for action among many. Another source of pressure is her Darwinian Dilemma ((2006) "A Darwinian Dilemma for Realist Theories of Value," Philosophical Studies 127(1): 109-66). The upshot of the Darwinian Dilemma is that we cannot cleave to nonreductive realism without acknowledging that most of our normative judgments are almost certainly false. Since any Moorean concerns about Street's constructivism pale in comparison to that unfortunate conclusion, we should opt for constructivism even if it only imperfectly captures the authority of reasons for action. This is an excellent strategy for responding to the open question argument, at least when the only alternative is nonreductive realism. When, however, other reductive or anti-realist views are in play - views that avoid the Darwinian Dilemma just as surely as Street's does - we should opt for the one that best captures the authority of reasons for action.

41 This would explain why she refers to the point of view of our normative judgments as "the practical point of view" (2010: 366).

42 Street comes closest to my view when she observes that "one way to present metaethical constructivism is as claiming that normative facts are constituted by facts about what is entailed by the 'rules of practical reason' in combination with the non-normative facts" (ibid.: 373). 
8.

In the opening chapter of On What Matters, Derek Parfit declares that "it is hard to explain the concept of a reason, or what the phrase 'a reason' means":

Facts give us reasons, we might say, when they count in favor of our having some attitude, or our acting in some way. But "counts in favor of" means roughly "gives a reason for." Like some other fundamental concepts, such as those involved in our thoughts about time, consciousness, and possibility, the concept of a reason is indefinable in the sense that it cannot be helpfully explained merely by using words. ${ }^{43}$

Here Parfit is echoing T. M. Scanlon, who begins What We Owe to Each Other with essentially the same thought:

Any attempt to explain what it is to be a reason for something seems to me to lead back to the same idea: a consideration that counts in favor of it. "Counts in favor how?" one might ask. "By providing a reason for it" seems to be the only answer. ${ }^{44}$

I hope that I have demonstrated just how much more we can say about what it is to be a reason, at least once we take seriously two ideas: first, that reasons are considerations that figure as premises in sound reasoning, and second, that reasoning is always governed by a substantive object or aim. How does a reason count in favor of some kind of response? By figuring in sound reasoning that concludes with that response. How precisely does a reason figure in that reasoning? By being evidence for the conclusion that the response in question best achieves the distinctive aim of the relevant sort of reasoning. 45

Matthew Silverstein

New York University Abu Dhabi

matthew.silverstein@nyu.edu

${ }_{43}$ D. Parfit (2011) On What Matters, Vol. 1, p. 31.

${ }^{44}$ Scanlon (1998: 17).

${ }^{45}$ I am indebted to Nic Bommarito, Kevin Coffey, David Enoch, Zoë Johnson King, Jessica Moss, David Owens, Gabriel Rabin, Mark Schroeder, Joshua Silverstein, Phyllis Silverstein, Daniel Star, Sharon Street, and David Velleman, as well as to two anonymous referees for the Journal of Ethics \& Social Pbilosophy, for helpful discussions of the ideas in this paper or comments on earlier drafts. Earlier versions of the paper were presented to workshops at NYU Abu Dhabi and Dartmouth College, to the Ethics Discussion Group at the University of Michigan, and at the W. Maurice Young Centre for Applied Ethics at the University of British Columbia. I received a great deal of helpful feedback on each of these occasions. Finally, special thanks to Sarah Paul and Nishi Shah for reading and commenting on multiple drafts and for various encouraging conversations. 